\title{
Algumas notas sobre educação e ética à luz do pensamento de Kant
}

\author{
Some notes on education and ethics in the light of the thought of Kant
}

\author{
Algunas notas sobre la educación y la ética a la luz del pensamiento de Kant
}

\author{
EDMILSON MENEZES* \\ CARLOTA BOTO**
}

\begin{abstract}
RESUMO - O presente ensaio tem por objetivo estabelecer alguma reflexão sobre o tema da educação e da ética a partir da leitura acerca do pensamento pedagógico de Kant expresso no texto Sobre a pedagogia. O referido trabalho origina-se de um curso ministrado pelo filósofo junto à Universidade de Könisberg. É considerado pela literatura como um texto menor, em virtude inclusive de ter sido publicado postumamente por um de Kant - Theodor Rink -, a partir de notas e apontamentos tomados para as preleções do professor sobre temas concernentes à pedagogia. Compreende-se que o texto Sobre a pedagogia ilustra o modo pelo qual Kant pensava a educação. Iluminado pelos escritos de Rousseau, mas profundamente tributário da literatura da Ilustração, destaca-se no trabalho a busca de compreensão da questão da moralidade. Kant considera uma dimensão moral inclusive no ato de instruir, cuja âncora deve ser a transposição da natureza para preparar a maioridade do juízo, e a infância e a juventude para a vida na coletividade.
\end{abstract}

Palavras-chave - Educação. Moral. Instrução. Disciplina. Rousseau. Kant.

ABSTRACT - The present essay aims at providing some reflection on the theme of education and ethics from the reading about the pedagogical thinking of Kant expressed in the text About the pedagogy. The aforementioned work originates from a course given by the philosopher at the University of Könisberg. It is considered by literature as a smaller text, inclusively for having been posthumously published by a disciple of Kant - Theodor Rink -, from the professor's notes used at lectures on themes regarding the pedagogy. It is understood that the About the pedagogy text illustrates the way in which Kant thought about the education. Enlightened by the writings from Rousseau, but deeply tributary of the literature of the Illustration, the work towards the search for understanding the issue of morality stands out. Kant considers a moral dimension inclusively in the act of instructing, whose anchor must be the transposition of nature to prepare for the age of judgment and also to prepare the childhood and youth for life in the collective.

Keywords - Education. Moral. Discipline. Rousseau. Kant.

RESUMEN - El presente ensayo tiene el objetivo de establecer alguna reflexión sobre el tema de la educación y de la ética a partir de la lectura acerca del pensamiento pedagógico de Kant, expresado en el texto Sobre pedagogía. El referido trabajo se origina de un curso dado por el filósofo en la Universidad de Könisberg. Es considerado por la literatura un texto menor en virtud, inclusive, de haber sido publicado póstumamente por un discípulo de Kant Theodor Rink -, a partir de notas y apuntes tomados de las exposiciones del profesor sobre temas concernientes a la pedagogía. Se Comprende que el texto Sobre la pedagogía ilustra el modo como Kant pensaba sobre la educación. Iluminado por los escritos de Rousseau más profundamente tributario de la literatura de la Ilustración, se destaca en el trabajo la búsqueda por comprender la cuestión de la moralidad. Kant considera una dimensión moral, inclusive en el acto de instruir, cuya ancla debe ser la transposición de la naturaleza para preparar la mayoridad del juicio, y para preparar además, a la infancia y a la juventud para la vida en colectividad.

Palabras clave - Educación. Moral. Instrucción. Disciplina. Rousseau. Kant.

\footnotetext{
*Doutor em Filosofia pela Universidade Estadual de Campinas (São Paulo, Campinas, Brasil) e Professor da Universidade Federal de Sergipe. E-mail: <ed.menezes@uol.com.br>.

**Doutora em História Social pela Universidade de São Paulo (São Paulo, SP, Brasil) e Professora da Universidade de São Paulo (São Paulo, SP, Brasil) E-mail: <carlotaboto@gmail.com>.
} 
$\mathrm{Na}$ educação tudo depende de uma coisa: que sejam estabelecidos bons princípios e que sejam compreendidos e aceitos pelas crianças. Estas devem aprender a substituir ao ódio o horror do que é nojento e inconveniente; a aversão interior em lugar da aversão exterior diante dos homens e das punições divinas; a estima de si mesmas e a dignidade interior em lugar da opinião dos homens; o valor intrínseco do comportamento e das ações em lugar das palavras e dos movimentos da indole; o entendimento em lugar do sentimento; a alegria e serenidade no bom humor em lugar da devoção triste, temerosa e tenebrosa. Mas é preciso, antes de mais nada, preservar os jovens do perigo de estimar demais os méritos da sorte (KANT, 2002, p. 96).

\section{INTRODUÇÃO}

O presente artigo tem como propósito refletir sobre a concepção de moral em Kant, especialmente à luz de uma leitura da Fundamentação da metafísica dos costumes, procurando relacionar a acepção kantiana de ética com o clássico opúsculo Resposta à pergunta: o que é o Iluminismo. Assim, da conexão entre conhecimento e moralidade, passa-se a meditar sobre o lugar da educação, tomando por referência o texto Sobre a pedagogia. O trabalho - do ponto de vista metodológico - procura alicerçar a análise de suas fontes em uma revisão da literatura disponível sobre o tema e tem por objetivo principal descortinar as relações entre a formação ética e a concepção de educação no pensamento kantiano. Busca compreender qual a herança de Rousseau no pensamento pedagógico kantiano e quais implicações isso teria do ponto de vista prático, à luz de sua acepção de moralidade. Finalmente, o texto volta-se para pensar a atualidade da reflexão kantiana, tanto do ponto de vista da ética quanto no que toca à dimensão pedagógica.

O homem a todo o momento depara-se com problemas que envolvem questões sobre compromisso, fidelidade, mentira, traição, solidariedade, etc. Com efeito, em todos os temas listados, o outro aparece implicitamente. Só se é solidário para com alguém; só se trai o outro etc. Em todos esses casos lidamos com problemas práticos, ou seja, com problemas que se apresentam nas relações efetivas entre pessoas ou quando se julgam certas decisões e ações das mesmas. Trata-se, por sua vez, de problemas cuja solução não concerne somente ao indivíduo que os propõe, mas, também, a outro ou outros indivíduos que sofrerão as consequências da sua decisão e da sua ação. As implicações podem afetar somente uma pessoa; em muitos casos, estamos diante de ações que atingem várias pessoas ou grupos sociais. Enfim, as consequências podem estender-se a uma comunidade inteira.

Esses problemas práticos, dos quais ninguém pode se eximir, para serem resolvidos, exigem que os indivíduos recorram a normas, cumpram determinados atos, formem juízos e, às vezes, se utilizem de determinados argumentos ou razões para justificar a decisão tomada.

Tudo isso faz parte de um tipo de comportamento efetivo, tanto das pessoas quanto dos grupos sociais. Quando o campo individual se pronuncia, estamos diante da consciência moral, ou seja, do conjunto das exigências, das prescrições que reputamos válidas para guiar nossas ações. Assim como nossa consciência estética parece reconhecer, espontaneamente, valores de beleza, nossa consciência lógica valores de verdade, nossa consciência moral estabelece juízo acerca do valor atinente aos nossos atos. Antes de agirmos, esses juízos se nos apresentam sob a forma de uma exigência; após a ação, eles se traduzem por um sentimento de satisfação ou pesar. Assim, ao lado do mundo dos acontecimentos, existe, por conseguinte, um mundo dos valores; e o termo moral designa a experiência moral vivida ou a reflexão filosófica sobre essa experiência determinada. A moral, no sentido de reflexão filosófica sobre a vida moral, denomina-se igualmente ética, e quando o coletivo é visado a ética assume posição de destaque. Sem embargo, o fato inelutável das interações travadas entre as pessoas nos coloca na posição de eternos estudiosos dos problemas éticos e morais. Nesse sentido, qualquer iniciativa que vise a um aprofundamento de tais questões se justifica pelo fato de precisarmos refletir acerca de uma realidade que exige de todos nós compromisso e determinação, para que o cotidiano não acabe nos sugando irrefletidamente. Além do mais, essa iniciativa tem por objetivo um estudo aprofundado acerca da ética enquanto expressão da conduta humana, o que nos leva a crer que ao relacionar ética e educação estaremos diante de um campo fecundo de trabalho e de meditação.

\section{A AUTONOMIA MORAL COMO CRITÉRIO DA LIBERDADE}

Se buscarmos na Modernidade a compreensão, no estudo da ética, da universalidade da categoria moral, chegaremos, sem qualquer dúvida, ao pensamento de Kant (MENEZES, 1992, 2000, 2010).

O filósofo considera que refletir sobre o tema da ética significa reportar-se à própria acepção de liberdade. Mas é preciso ter cautela com a noção de liberdade na filosofia moral de Kant. Diz Thouard que "o sujeito kantiano é livre quando consegue se desprender de seus desejos espontâneos e não quando lhes obedece" (2004, p. 125). De acordo com o comentário de Luc Ferry sobre a razão 
prática kantiana: "é por ser livre, e não prisioneiro de um código natural ou histórico determinista, que o ser humano é um ser moral" (2009, p. 97). A liberdade em Kant ganha estatuto filosófico; mas, ao mesmo tempo, como observa Otfried Höffe, "só a capacidade de agir de acordo com leis representadas por si mesmas funda uma vontade própria. A vontade designa a capacidade de, em verdade, não extinguir os impulsos naturais e sim distanciar-se deles e de suspendê-los como fundamento determinante último" (2005, p. 189). De todo modo, as ideias de intenção e de vontade são cruciais para compreender a moral kantiana. A ação boa é conduzida por uma vontade correspondente - “devo querer agir assim” (TUGENDHAT, 2000, p. 119).

Kant inicia a primeira seção de sua Fundamentação da metafísica dos costumes dizendo que a única coisa que pode ser considerada boa de maneira ilimitada é a "boa vontade" (1988, p. 21). Todos os demais atributos do espírito ou do temperamento - tais como discernimento, argúcia, capacidade de julgar, coragem, decisão, constância de propósitos - podem ser usados para o bem ou para o mal. Mas a boa vontade tem valor em si mesma porque, por definição, dirige-se para o bem. Kant dirá sobre o assunto:

A boa vontade não é boa por aquilo que promove ou realiza, pela aptidão para alcançar qualquer finalidade proposta, mas tão somente pelo querer, isto é, em si mesma, e, considerada em si mesma, deve ser avaliada em grau muito mais alto do que tudo o que por seu intermédio possa ser alcançado em proveito de qualquer inclinação, ou mesmo, se se quiser, da soma de todas as inclinações (1988, p. 23).

O conceito de boa vontade é, por si próprio, desvinculado do resultado da ação; porque a boa vontade se atém apenas ao seu princípio. De todo modo, Kant considera que a ação só será moral quando movida por uma vontade boa. Portanto, a moralidade da ação nada terá a ver com o efeito acarretado pela mesma. Quando praticamos, todavia, uma ação, afastando-nos, por meio dela, de nossos impulsos e inclinações, nós a realizaremos por simples dever. Kant diz que "só então é que ela teria o seu autêntico valor moral" (1988, p. 28).

A tese que norteia, portanto, a moral kantiana é o querer "que a minha máxima se torne uma lei universal" (KANT, 1988, p. 33). Desse modo, aquilo que minha vontade postula para mim deverá ser equivalente ao que eu quero para toda a humanidade. $\mathrm{O}$ dever assume, por ser assim, caráter de universalidade. Nos termos de Kant: "age como se a máxima da tua ação se devesse tornar, pela tua vontade, em lei universal da natureza" (1988, p. 33). Existe - na perspectiva kantiana - uma disposição de racionalidade prática, dirigida para a apreensão das leis da vontade, no território dos julgamentos da conduta ética. Nesse sentido, a universalidade do critério moral é um postulado.

Tudo na natureza age segundo leis. Só um ser racional tem a capacidade de agir segundo a representação das leis, isto é, segundo princípios, ou: só ele tem uma vontade. Como para derivar as ações das leis é necessária a razão, a vontade não é outra coisa senão razão prática. Se a razão determina infalivelmente a vontade, as razões de tal ser, que são conhecidas como objetivamente necessárias, são também subjetivamente necessárias, isto é, a vontade é a faculdade de escolher só aquilo que a razão, independentemente da inclinação, reconhece como praticamente necessário, quer dizer, como bom (KANT, 1988, p. 47).

Como assinala Crampe-Casnabet, o imperativo categórico que está na base da moral kantiana é posto como lei; sendo, portanto, universal: "ordena incondicionalmente à vontade purificada de todo móvel sensível, de todo fim singular. Tem como lugar a ética" (1994, p. 73). Sobre o tema dessa representação da lei e da capacidade humana de agir segundo a mesma lei, Lebrun destaca que, no argumento da teoria moral kantiana,

É a razão prática que nos possibilita a ideia de um objetivo final. É porque sei de antemão que o homem, enquanto submetido à moralidade, é um fim em si, que posso ter a certeza de que sua existência não foi criada em vista de outra coisa, sendo, pois, a única que dá um conteúdo ao conceito de objetivo final. Tudo repousa sobre a consciência do fato moral (2001, p. 102).

É importante destacar que, como observa sobre o tema John Rawls, "Kant faz uma distinção entre as ações que concordam com o dever e são realizadas segundo o dever e as ações que concordam com o dever, mas nascem da inclinação. As últimas possuem legalidade, mas não moralidade" (2005, p. 204). Uma ação praticada por dever tem seu valor moral, não no propósito que com ela se quer atingir, mas na máxima que a determina; não depende, portanto, da realidade do objeto da ação, mas somente do princípio do querer segundo o qual a ação, abstraindo de todos os objetos da faculdade de desejar, foi praticada. Quando se fala de valor moral, não é das ações visíveis que se trata, mas dos seus princípios íntimos. Embora as primeiras sejam importantes, elas são determinadas pelos segundos e possuem um valor relativo em termos de julgamento moral. Tudo isso corrobora para que as ações moralmente relevantes tornem-se difíceis de serem implementadas e avaliadas, formando-se, assim, dois universos de análise: a moralidade e a legalidade. "O essencial de todo o valor moral das ações é que a lei moral determina imediatamente a vontade. Se a determinação da vontade acontece em conformidade à lei moral, mas só mediante um sentimento, não importa de que espécie, 
[...], por conseguinte, não por causa da lei, a ação terá certamente legalidade, mas não moralidade" (KANT, 1988, p. 87). A lei moral, ela própria, deve ser o móbil, o motivo do querer. Tem-se a moralidade quando a ação é cumprida por dever. Tem-se, ao contrário, a pura e simples legalidade, quando a ação é conforme ao dever. Dito de outra forma, a legislação moral é aquela que não admite uma ação efetuada segundo as inclinações e os interesses. De maneira diferente, a legislação jurídica aceita apenas a conformidade da ação à lei e não se interessa pelos seus móbeis determinantes. A pura moralidade se coaduna com uma vontade cujo respeito está voltado apenas para seus fins, isto é, uma vontade que não está determinada por atitude alguma e por cálculo interessado algum, mas apenas pelo respeito ao dever.

Nesse sentido, a ação poderá ser caracterizada como moral se e somente se não for movida pela necessidade e nem pela inclinação. Diz Rawls que

Kant considera que os deveres de justiça (determinados por um sistema de leis justas) são aqueles que podem ser externamente legislados e impingidos, ou impostos a nós por outrem - por exemplo, sendo sancionados por recompensas e punições. Esses deveres exigem apenas atos específicos de vários tipos, que podem ser realizados por quaisquer motivos, inclusive (como observado acima) por motivos de interesse próprio de todas as espécies. Ao contrário, os deveres éticos não nos podem ser externamente impostos; cumpre que os imponhamos a nós mesmos (através de uma legislação interna, por assim dizer) (RAWLS, 2005, p. 215)

Daí também a distinção estabelecida por Kant entre moral e direito: "o âmbito da moralidade diz respeito à liberdade interna, o do direito se amplia para a liberdade externa". Pode-se ainda falar, com Kant, de uma liberdade moral, distinta da liberdade jurídica (BOBBIO, 2000, p. 95). Nesse sentido - como observa Bobbio:

Por liberdade moral deve ser entendida, segundo Kant, a faculdade de adequação às leis que a nossa razão dá a nós mesmos; por "liberdade jurídica", a faculdade de agirmos no mundo externo, não sendo impedidos pela liberdade igual dos demais seres humanos, livres como nós, interna e externamente. Se por "liberdade" se entende, numa das operações mais comuns, a faculdade de fazer algo sem ser coagido ou liberdade como "não coação", ou como "liberdade de...", liberdade moral é a liberdade dos impedimentos que provêm de nós mesmos (as inclinações, as paixões, os interesses), é liberação interior, esforço de adequação à lei eliminando os obstáculos que derivam de nossa faculdade de desejar; liberdade jurídica, porém, é a liberação dos impedimentos que provêm dos outros, é liberação exterior, ou seja, eficaz no domínio do mundo externo (2000, p. 96).
No domínio da moralidade, o bom e o bem são atos determinados pela vontade prática por representação da razão. Nesse sentido, diferentemente dos imperativos de destreza ou de prudência, o imperativo moral é categórico e deve ser consoante a outro critério também determinante de sua universalidade conceitual: "age de tal maneira que uses a Humanidade, tanto na tua pessoa como na pessoa de qualquer outro, sempre e simultaneamente como fim e nunca simplesmente como meio" (KANT, 1988, p. 69).

A perspectiva kantiana supõe que seja "justamente porque podemos, enquanto pessoas razoáveis e racionais, ver a nós mesmos como legisladores do conteúdo do imperativo categórico (tal como se aplica a nós) que estamos legitimamente sujeitos a suas exigências (RAWLS, 2005, p. 236). E isso também só acontece porque possuímos a liberdade da vontade. Porém, é preciso educar o sujeito para usufruir da liberdade e para agir como ser moral de vontade autônoma. ${ }^{1}$

\section{LIBERDADE MORAL, FORMAÇÃO HUMANA, DISCIPLINA E INSTRUÇÃO}

O trabalho de Kant Sobre a pedagogia é originário de curso proferido pelo filósofo na Universidade de Könisberg. Foi publicado por um discípulo seu - Theodor Rink - a partir de notas tomadas para as preleções do professor sobre temas atinentes à educação. Philonenko (2004, p. 12) alerta que "se ignora a maneira exata pela qual Rink compreendeu sua função de editor: não se sabe se ele publicou integralmente os textos que Kant lhe havia enviado; ignora-se particularmente se a ordem pela qual se dispôs o texto era aquela determinada pelo manuscrito". De todo modo, sabe-se que a Universidade de Königsberg previa que os cursos fossem estruturados a partir de leituras comentadas. Para a matéria específica de Pedagogia, previa-se a utilização de textos de Basedow e de Bock. Mas, ao que consta, Kant não se teria detido estritamente em nenhum desses dois autores. Pelo contrário: sua grande inspiração pedagógica teria sido fruto da leitura do Emílio. No comentário de Philonenko:

Como Rousseau, Kant recomenda que se cesse de aprender pensamentos; é necessário aprender a pensar. Não se trata de aprender o conteúdo de um livro - um texto deve ser considerado como um pretexto, como um manancial de questões. Mas, além disso, Kant distingue criteriosamente e pondera seu pensamento: não se deve acreditar que não há nada que deva ser propriamente falando - aprendido. É preciso apreender no sentido próprio do termo nas ciências históricas e matemáticas. Uma preocupação de equilíbrio e de bom senso dita a reflexão pedagógica de Kant (2004, p. 14). 
Diz ainda Philonenko que o texto de Kant Sobre a pedagogia demonstra claramente como, "por detrás do professor da universidade, existe um pedagogo realmente interessado nos problemas da educação" (2004, p. 13). E, mais do que isso, "por detrás do filósofo, existe um homem que pode ver concretamente as dificuldades da educação" (2004, p. 13).

Sobre a pedagogia é - no conjunto da obra kantiana - visto como um texto menor. ${ }^{2}$ Todavia, a preocupação pedagógica ali assinalada ecoa como um prolongamento da reflexão de Kant sobre a moral. Pode-se, talvez, dizer que, assim como a moral kantiana reconhecidamente teve inspiração na leitura do Emílio de Rousseau, também as ideias contidas no texto Sobre a pedagogia reportam-se ao pensamento do genebrino (POLLA, 2013).

Todavia, Kant oferece ao tema um tratamento próprio, chegando a enfatizar - como Rousseau não o fizera - a civilização dos costumes como o grande propósito da obra educativa. Já à partida, recorda que o atributo da educabilidade - como desenvolução - é próprio da espécie humana. Como observa Celso de Moraes Pinheiro sobre esse assunto, "que Rousseau tenha influenciado Kant não podemos pôr em dúvida. Apenas devemos estar atentos para as objeções e reservas que Kant faz a certos aspectos da pedagogia proposta por Rousseau no Emílio" (PINHEIRO, 2007, p. 46). Há diferenças, sobretudo, quanto ao julgamento dos dois autores relativamente aos procedimentos pedagógicos por eles sugeridos. Além disso - como observa Cauê Cardoso Polla - a perspectiva cosmopolita permeia o pensamento pedagógico kantiano.

Para Kant, educar é olhar para frente; e forçar o processo de saída do sujeito de sua situação anterior. A natureza é algo a ser transposto, tendo em vista a construção do ser humano autônomo e moral. Nesse sentido, pode-se dizer que

O processo de educação em Kant é um constante desafio de progresso. Ficar imobilizado no âmbito da animalidade é renunciar ao chamado próprio do homem. A necessidade de progresso em educação ao melhor é própria do homem. Ao provocar, no sujeito humano, a necessidade de progredir e de se livrar de sua situação de menoridade, Kant não visa apenas a uma crítica a Rousseau e, por meio dele, ao naturalismo que se mostra como uma espécie de conformismo sociopolítico, mas, sobretudo, àqueles que procuram fazer uma apologia da natureza ideal, idílica dos povos primitivos (PINHEIRO, 2007, p. 51).

Também Vandewalle considera importante verificar, não apenas a confluência, mas sobretudo as diferenças entre os propósitos pedagógicos de Kant e de Rousseau. Diz o autor que, "nesse aspecto, Kant mostrará uma evolução e se distanciará do naturalismo pedagógico, em benefício de um elogio da disciplina como elemento que pode dominar o que é mau na natureza infantil, a saber, o egoísmo e as inclinações sensíveis" (VANDEWALLE, 2005, p. 67).

A tarefa da pedagogia será por Kant qualificada a partir de uma multiplicidade de fatores: conservação, trato, disciplina, instrução e formação. Todo esse rol de atividades distintas é compreendido pela acepção de educação. Sendo assim, aquele que será educado se constituirá como "infante, educando e discípulo" (KANT, 2002, p. 11). A princípio, Kant vai ao encontro daquilo que disse quando - nos comentários que faz sobre o significado da Ilustração - apresenta a ideia da maioridade intelectual como critério para a ação autônoma. Em sua Resposta à pergunta: que é o Iluminismo? Kant destaca que a ilustração é a tarefa maior do homem; aquilo que possibilita a saída de sua menoridade. Menoridade, por sua vez, é definida como "a incapacidade de se servir do entendimento sem a orientação de outrem" (KANT, 1989, p. 11). O dístico do Iluminismo assinalará, pela mesma razão, para a necessária coragem de se servir autonomamente do próprio entendimento. Trata-se de ousar saber.

Kant compreende por "uso público da razão" (1989, p. 13) a disposição humana de se valer dos recursos intelectuais com que a natureza dotou o homem. Sem o desenvolvimento da razão, mediante a clivagem da cultura letrada, o ser humano não levará a contento sua própria vocação. Por isso mesmo, o filósofo considera que, embora se possa adiar a ilustração, "renunciar a ela, quer seja para si, quer ainda mais para a descendência, significa lesar e calçar aos pés o sagrado direito da humanidade" (KANT, 1989, p. 16). A instrução - e apenas ela - permitirá um alargamento da capacidade do homem. Será, pois, fundamental servir-se da própria razão em tudo que for assunto da consciência e do julgamento. Só isso poderá produzir um verdadeiro sopro de liberdade no espírito do homem e no espírito dos povos. Diz Kant sobre o tema:

Um grau maior de liberdade civil parece vantajoso para a liberdade de espírito do povo e, no entanto, estabelece-lhe limites intransponíveis; um grau menor cria-lhe, pelo contrário, o espaço para ela se alargar segundo toda a sua capacidade. Se, pois, a natureza, debaixo deste duro invólucro, desenvolveu o germe de que delicadamente cuida, a saber, a tendência e a vocação para o pensamento livre, então ela atua por sua vez gradualmente sobre o modo de sentir do povo (pelo que este tornar-se-á cada vez mais capaz de agir segundo a liberdade) e, por fim, até mesmo sobre os princípios do governo, que acha salutar para si próprio tratar o homem, que agora é mais do que uma máquina, segundo a sua dignidade (KANT, 1989, p. 19). 
Tal disposição do espírito a uma dignidade coloca o incondicionado acima de qualquer preço. A legislação que determina todo o valor deve ter, precisamente, para isso uma dignidade, quer dizer, um valor incondicionado, incomparável. A autonomia é, portanto, o princípio da dignidade da natureza humana e de toda natureza racional. Somente a dignidade da humanidade, enquanto natureza racional, independentemente de todo o fim a ser alcançado, e, por consequência, o respeito por uma simples ideia, serve de prescrição moral. A pessoa que cumpre todos os seus deveres possui uma sublimidade e uma dignidade, na medida em que ela é legisladora de si mesma. A dignidade da humanidade consiste na faculdade que ela possui de estabelecer leis universais, à condição, entretanto, de ser, ao mesmo tempo, submissa a essa legislação.

Em Sobre a pedagogia, Kant realça a transformação da animalidade em Humanidade como tarefa precípua da ação educativa. Por não ser submetido necessariamente a instintos, por ser capaz de se afastar das próprias inclinações, o homem constrói a autonomia de sua identidade. Nessa condição ele trilhará sua relação com o futuro. Antes que ele esteja, porém, apto a pensar por si próprio, outros farão isso. Cumprirá ao adulto educador preservar a criança da animalidade que lhe é intrínseca, com o fito de que ela não venha a fazer uso nocivo de suas próprias forças. Ser selvagem - argumenta Kant é ser independente de qualquer lei. Caberá às gerações adultas proceder, frente às mais jovens, incutindo-lhes hábitos de disciplina, com o intuito de transformar em face humana a dimensão animal que caracteriza o ser. De alguma maneira, a escola servirá, dentre outras coisas, também para isso.

A dignidade e a autonomia também requisitam a educação. Esta deve acentuar que "o homem possui interiormente uma dignidade que o enobrece aos olhos de todas as outras criaturas, e é seu dever não renunciar a esta condição presente em sua pessoa" (KANT, 2002, p. 95; tradução modificada). Pela educação compreendemos que o mundo não está centrado em nós nem podemos trazê-lo inteiro conosco, mas dele somos dignos enquanto cidadãos. A isso não podemos renunciar, sob pena de renegar o nosso estatuto humano. Desse modo, poderíamos perguntar: em que consiste a verdadeira dignidade do educando? No fato de que ele é um ser racional, um ser portanto que não deve estimar-se a não ser de acordo com a razão. Trataremos a criança, por conseguinte, a partir desse princípio e procuraremos distanciá-la, ao mesmo tempo, da falsa humildade e da vaidade, que são os dois contrários da dignidade. Pois a falsa humildade, assim como a vaidade, consiste em estimar não em função dos conceitos da razão, não em função daquilo que é, como quer a dignidade, mas em função do julgamento dos outros, da opinião, enfim, da aparência. À moral e à antropologia acrescenta-se a educação (MENEZES, 2010, p. 207).

Para entender o mundo não basta uma atitude intelectual espontânea. É imprescindível partir de um alto senso de coletividade: as liberdades individuais devem disciplinar-se em vista de um bem maior, o coletivo.

A disciplina é, sob tal aspecto, compreendida como hábito a ser incutido desde muito cedo, até porque seu propósito é mudar o homem - e criar nele a condição do autodomínio. Com natural tendência à liberdade, "quando se deixou o homem seguir plenamente a sua vontade durante toda a juventude e não se lhe resistiu em nada, ele conserva certa selvageria por toda a vida" (KANT, 2002, p. 14). Na relação educação moral e liberdade diz Dalbosco -, "Kant concebe o constrangimento da liberdade do educando por meio da disciplina como uma etapa necessária para se chegar à moralidade, que é o fim último e a tarefa mais nobre da ação educativa e da própria ação humana" (DALBOSCO, 2009, p. 31). Nesse sentido, o argumento de Dalbosco prossegue, identificando a necessidade de um ato coativo imposto externamente para firmar e formar a conquista da liberdade interna e do autodomínio. Kant acredita que a juventude precisa encontrar resistência a impulsos, à manifestação de seus desejos e a seus ímpetos. De alguma maneira, educar é forjar transformações. Formar significará, para a pedagogia kantiana, tanto disciplinar quanto instruir. A condição humana é uma conquista que requer, no limite, esforço civilizatório. Disciplinar, para Kant, seria "acostumar o homem a se submeter aos ditames da razão" (DALBOSCO, 2004, p. 7).

Diz Kant sobre o tema:

O homem não pode se tornar um verdadeiro homem senão pela educação. Ele é aquilo que a educação dele faz. Note-se que ele só pode receber tal educação de outros homens, os quais a receberam igualmente de outros. Portanto, a falta de disciplina e de instrução em certos homens os torna mestres muitos ruins de seus educandos. Se um ser de natureza superior tomasse cuidado da nossa educação, ver-se-ia, então, o que poderíamos nos tornar. Mas, assim como, por um lado, a educação ensina alguma coisa aos homens e, por outro lado, não faz mais que desenvolver nele certas qualidades, não se pode saber até aonde nos levariam nossas disposições naturais (2002, p. 15).

A falta de disciplina equivaleria à falta de cultura. Tornaria mais rude o ser humano. Educar é, pelo contrário, empreendimento voltado para que cada geração possa caminhar um passo em direção ao aperfeiçoamento da Humanidade. O germe de Humanidade não se desenvolve naturalmente por força de disposições inatas 
ao desenvolvimento e ao caráter humano. O caráter singular do homem é traduzido pela possibilidade de "tentar conseguir o seu fim; o que ele não pode fazer sem antes ter dele um conceito" (KANT, 2002, p. 18). Kant define ideia como conceito perfeito de algo ainda não localizado na experiência. Nesse sentido, trata-se de categoria reguladora do real e da imagem projetada do futuro. Este, por sua vez, toma por ponto de partida expectativas presentes geradas pela experiência passada.

Educar seria, para Kant, desenvolver finalidades; como se a Providência assim se dirigisse à Humanidade: "entra no mundo. Coloquei em ti toda espécie de disposições para o bem. Agora compete somente a ti desenvolvê-las, e a tua felicidade ou infelicidade depende de ti" (KANT, 2002, p. 19). A Providência não ofereceu alega Kant - as marcas distintivas que dirigem os homens para o caminho do bem. A moralidade é, pois, construída:

O homem deve, antes de tudo, desenvolver as suas disposições, para o bem; a Providência não as colocou nele prontas; são simples disposições, sem a marca distintiva da moral. Tornar-se melhor, educarse e, se se é mau, produzir em si a moralidade: eis o dever do homem. Desde que se reflita detidamente a respeito, é o maior e o mais árduo problema que pode ser proposto aos homens. De fato os conhecimentos dependem da educação, e esta, por sua vez, depende daqueles. Por isso, a educação não poderia dar um passo à frente a não ser pouco a pouco, e somente pode surgir um conceito da arte de educar na medida em que cada geração transmite suas experiências e seus conhecimentos à geração seguinte; a qual lhes acrescenta algo de seu e os transmite à geração que lhe segue (KANT, 2002, p. 20).

\section{A Moralidade COMO CONSTRUÇÃo PEDAGÓGICA}

Como arte, a educação é artifício construído por mãos humanas. Kant considera que não existe qualquer instinto para tal finalidade. Educar é uma das mais difíceis artes de cuja habilidade dispõe o ser humano (KANT, 2002, p. 20). A educação poderá ser "mecânica, ordenada sem plano, conforme as circunstâncias, ou raciocinada" (idem, p. 21). Embora considere que pedagogia raciocinada é aquela que desenvolve a natureza do homem para que este venha a alcançar seu destino, Kant sustenta-se, também nesse assunto, numa ideia bem marcada de progresso. Antes de tudo, será imprescindível tornar a educação prática cientificamente ancorada, de maneira a que seus esforços sejam coerentes com determinados ideais e obras valorizados pelas gerações adultas. Do contrário, "uma geração poderia destruir tudo o que outra anterior tivesse edificado" (KANT, 2002, p. 22). ${ }^{3}$ Além disso, nas próprias palavras de Kant, percebe-se a necessidade de se fortalecer o vínculo entre a prática pedagógica e os prospectos de futuro de cada sociedade; no seguinte sentido:

Um princípio de pedagogia, o qual mormente os homens que propõem planos para a arte de educar deveriam ter ante os olhos, é: não se deve educar as crianças segundo o presente estado da espécie humana, mas segundo um estado melhor, possível no futuro, isto é, segundo a ideia de Humanidade e da sua inteira destinação. Esse princípio é de máxima importância. De modo geral, os pais educam seus filhos para o mundo presente, ainda que seja corrupto. Ao contrário, deveriam dar-lhes uma educação melhor, para que possa acontecer um estado melhor no futuro (KANT, 2002, p. 22).

Se a educação intencional é aquela que se deverá voltar para o futuro, caberá dirigir esforços coletivos com o fito de estabelecer um projeto educativo de dimensão cosmopolita. Mais do que isso: tal empreendimento será, antes de tudo, matéria de escola. Educadores, zelosos pelo desenvolvimento da Humanidade, deverão, por definição, "conduzir a posteridade a um grau mais elevado" (KANT, 2002, p. 25), para o qual se compreende o fato de ser simultaneamente mais hábil e mais moral.

É de se pensar os funestos efeitos que poderiam ser vislumbrados caso a sociedade, incapaz de estabelecer diálogo com projetos de futuro, eternizasse seu imaginário no tempo presente. Para a perspectiva kantiana, isso eliminaria da agenda social o projeto educativo. Os jovens não podem nem devem ser educados para perpetuar um interminável hoje. Sem a referência de algum amanhã, a educação estaria indelevelmente condenada ao fracasso, tanto no aspecto cognitivo quanto na dimensão moral. Como sublinha Cauê Cardoso Polla, em Kant, "a educação é, portanto, método, o caminho que o homem tem que trilhar para atingir o uso pleno de sua razão e assim sua destinação enquanto humanidade" (POLLA, 2013, p. 92).

Kant valoriza alguns atributos tidos por fundamentais para regular o ato educativo; critérios norteadores da ação, podendo ser compreendidos em relação àquele que educa, mas, sobretudo, em relação aos que são educados.

O primeiro requisito consiste na formação do "ser disciplinado"; ou seja, "impedir que a animalidade prejudique o caráter humano, tanto no indivíduo como na sociedade. A disciplina consiste em domar a selvageria" (KANT, 2002, p. 25). O segundo critério será - para Kant "tornar-se culto", compreendendo-se aqui a cultura como criação de habilidades ou posse de algumas capacidades consideradas condizentes com necessidade específicas do desenvolvimento e aprimoramento humano. A ideia de cultura é por Kant identificada com o modelo ocidental de cultural letrada. 
Para exercer lugar influente do ponto de vista social será importante que o homem seja também prudente. Kant situará a acepção de prudência no território da civilidade: "esta requer certos modos corteses, gentileza e a prudência de nos servirmos dos outros homens para os nossos fins. Ela se regula pelo gosto mutável de cada época (Kant, 2002, p. 26)". Finalmente - observa Kant - deve-se cuidar da moralização. Escolher os bons fins significa dirigirse a finalidades aprovadas por todos e que podem ser, por seu turno, consideradas também "os fins de cada um" (Kant, 2002, p. 27). Para isso, será imprescindível que se ensinem as crianças a pensar. Como assinala Vandewalle, "Kant põe no centro de sua pedagogia uma aprendizagem, não de pensamentos, mas do pensamento em si. Não se trata de aprender conteúdos propostos pelo mestre, mas de aprender a exercer uma faculdade ativa, que é o pensamento" (VANDEWALLE, 2005, p. 60). Educar é, sob tal aspecto, formar o juízo crítico da juventude: uma "capacidade intelectual que passa, antes de tudo, pela aptidão de se forjar um juízo pessoal - plantar, diz Kant, as fecundas raízes do conhecimento, mais do que os conhecimentos mesmos" (VANDEWALLE, 2005, p.60). Diz ainda Vandewalle que - na perspectiva da pedagogia kantiana - a filosofia é apresentada como uma "faculdade ativa de reflexão, posta em jogo em cada ocasião, mais do que um corpo de conceitos determinados sujeitos de serem aprendidos e memorizados" (VANDEWALLE, 2005 , p. 60). Por isso é que - nas palavras de Kant "não é suficiente treinar as crianças; urge que aprendam a pensar. Devem-se observar os princípios dos quais todas as ações derivam" (KANT, 2002, p. 27).

Um aspecto central que vincula a perspectiva pedagógica de Kant à sua teoria moral reside exatamente na veemente recomendação que ele faz para que o mal seja recusado em si mesmo, e não apenas porque Deus o proibiu. Nas palavras do filósofo:

Mas como é infinitamente importante ensinar às crianças a odiar o vício por virtude, não pela simples razão de que Deus o proibiu, mas por ser desprezível por si mesmo! De outro modo, elas pensariam facilmente que o vício poderia ser praticado e que seria permitido, se Deus não o houvesse proibido, e que Deus bem poderia fazer uma exceção em seu favor. Deus é o ser soberanamente santo e não quer senão o que é bom, e exige que pratiquemos a virtude pelo seu valor intrínseco e não porque Ele o ordena (KANT, 2002, p. 27-28).

Kant considera que vivia em uma época "de disciplina, de cultura e de civilização" (2002, p. 28), mas não ainda de verdadeira moralidade. Como se sabe, a acepção kantiana de moral corresponde a uma disposição emanada da estrutura da racionalidade. Sendo assim: "fazer algo por dever equivale a obedecer à razão" (KANT, 2002, p. 80). Não se deverá falar do dever às crianças; mas guiá-las pelo dever. A ideia de dever é, para Kant, uma necessidade: precisamos dela. Educar e instruir supõem - como a vida - a construção de ações reguladas por princípios.

Kant conceitua de maneira completamente diferente de Rousseau ${ }^{4}$ a ideia de educação negativa. Do ponto de vista kantiano, ao educar, deparamo-nos com a urgência de agir com vistas ao cultivo do ser autônomo. Nessa direção, há uma negatividade pedagógica. Esta, porém, consiste justamente em disciplinar espírito e corpo do educando. Kant fará - acerca do tema - um "elogio da disciplina como elemento que pode dominar o que é mau na natureza infantil, a saber, o egoísmo e as inclinações sensíveis" (VANDEWALLE, 2005, p. 67). Nesse sentido, o lugar ocupado pela disciplina na formação kantiana será o de "possibilitar à criança a compreensão dessas regras, pois desse aprendizado surgirá a capacidade de o homem aceitar suas próprias leis autônomas e também todo o conjunto de leis do Estado" (PINHEIRO, 2007, p. 77). Formar, nesse sentido, é proceder a ação negativa; "ou seja, disciplina, a qual impede os defeitos" (KANT, 2002, p. 29). Mas é também dirigir outra obra: esta positiva, compreendida pela instrução e pela direção atribuída pela cultura. Tal direcionamento:

[...] é a condução na prática daquilo que foi ensinado. Daqui nasce a diferença entre o professor - que é simplesmente um mestre - e o governante, o qual é um guia. O primeiro ministra a educação da escola; o segundo, a da vida. O primeiro período para o educando é aquele em que deve mostrar sujeição e obediência passivamente; no segundo, lhe é permitido usar a sua reflexão e a sua liberdade, desde que submeta uma e outra a certas regras. No primeiro período, o constrangimento é mecânico; no segundo, é moral (KANT, 2002, p. 29-30).

Em relação ao período para o qual se deve prever a ação educativa, Kant dirá: "até o momento em que a natureza determinou que o homem governe a si mesmo" (2002, p. 32), ou seja, enquanto o educando ainda não puder julgar por si próprio. Até os dezesseis anos o educando habituar-se-á a "conciliar a submissão ao constrangimento das leis com o exercício da liberdade" (KANT, 2002, p. 32). Nesses primeiros dezesseis anos de vida, o ser humano não sabe utilizar adequadamente sua liberdade. Não tem autonomia para tanto; e estará, portanto, sob o constrangimento de outrem. A questão colocada pelo filósofo é a seguinte: como se poderá conciliar - no ato educativo - o constrangimento das leis com o exercício da liberdade? Diz Kant sobre o tema que 
É preciso habituar o educando a suportar que a sua liberdade seja submetida ao constrangimento de outrem e que, ao mesmo tempo, dirija corretamente a sua liberdade. Sem essa condição, não haverá nele senão algo mecânico; e o homem, terminada a sua educação, não saberá usar sua liberdade. É necessário que ele sinta logo a inevitável resistência da sociedade, para que aprenda a conhecer o quanto é difícil bastarse a si mesmo, tolerar as privações e adquirir o que é necessário para tornar-se independente (KANT, 2002, p. 33).

Kant também aqui, ao abordar os critérios da formação da criança, é bastante tributário da leitura de Rousseau, expondo, quase literalmente, muitas das convicções do educador genebrino. Um exemplo disso é quando comenta da improcedência de os adultos se dobrarem aos desejos e impulsos imediatos das crianças; e, em vez de dirigir suas vontades, cederem frente a todos os anseios infantis. Kant empresta, na ocasião, quase literalmente, o pensamento do Rousseau do Emílio: " "não é natural que ela comande com seus gritos e que o forte obedeça ao fraco" (KANT, 2002, p. 73). Além disso, acrescenta o texto Sobre a pedagogia: "se se permite às crianças tudo obter pelos gritos, tornamse más; se conseguem tudo com súplicas, elas se tornam suscetíveis" (p. 74). A remissão de Kant à pedagogia rousseauniana é indisfarçável. Rousseau (1979, p. 80) já dissera que a infância precisa "amadurecer nas crianças", ${ }^{6}$ e que não se deverá apressar o ritmo com o risco de formar crianças velhas. Tal perspectiva é sublinhada no trecho abaixo:

Uma criança não deve ter senão a prudência de uma criança; e não deve se transformar num imitador cego. Ora, uma criança que apresenta as máximas do senso próprio de homens feitos está fora do caminho traçado para sua idade e não faz senão imitar. Ela deve ter apenas a inteligência de uma criança e não deve se pôr em evidência muito cedo. Uma criança assim conformada não se tornará jamais um homem ilustrado e de mente serena. É igualmente insuportável que uma criança queira seguir toda moda, por exemplo, cortar a barba, usar pulseiras e também uma tabaqueira. Tornase desse modo uma pessoa afetada, o que não fica bem numa criança (KANT, 2002, p. 83).

Kant considera importante resistir com firmeza aos desejos espontâneos das crianças, de maneira a poder, num primeiro momento, discipliná-las; em seguida, moralizá-las. Da inclinação contida pela disciplina, será engendrado o autodomínio, a capacidade de resistir ao impulso, a habilidade de controlar as próprias afeições. Kant compreende que são duas práticas diferentes, porém complementares: disciplina e moralização. A criança precisa aprender a agir segundo máximas. A disciplina é apenas hábito - e, ainda que necessária, é, enquanto tal, insuficiente. $\mathrm{O}$ discernimento construído mediante exercício de reflexão sobre máximas inscritas em suas ações levará a criança a progressivamente formar os alicerces de seu caráter. E o caráter nada mais é do que a "aptidão para agir segundo máximas" (PHILONENKO, 2004, p. 81). Nas palavras de Kant:

A cultura moral deve-se fundar sobre máximas, não sobre a disciplina. Esta impede os defeitos; aquelas formam a maneira de pensar. É preciso proceder de tal modo que a criança se acostume a agir segundo máximas, e não segundo certos motivos. A disciplina não gera senão um hábito, que desaparece com os anos. É necessário que a criança aprenda a agir segundo certas máximas, cuja equidade ela própria distinga. [...] As máximas são deduzidas do próprio homem. Deve-se procurar desde cedo inculcar nas crianças, mediante a cultura moral, a ideia do que é bom ou mal. Se se quer fundar a moralidade, não se deve punir. A moralidade é algo tão santo e sublime que não se deve rebaixá-la, nem igualá-la à disciplina. O primeiro esforço da cultura moral é lançar os fundamentos da formação do caráter. O caráter consiste no hábito de agir segundo certas máximas. Estas são, em princípio, as da escola e, mais tarde, as da Humanidade. Em princípio, a criança obedece a leis. Até as máximas são leis, mas subjetivas; elas derivam da própria inteligência do homem (KANT, 2002, p. 75-76).

Não se poderá cobrar da infância a consistência que se pode exigir da idade madura. Crianças são aprendizes. ${ }^{7}$ Por isso, há de se valorizar o elemento da obediência a normas, como expressão de suas atitudes. Obedecese, em primeira instância, à vontade absoluta de um governante legitimamente constituído. No momento seguinte, a obediência ocorrerá pela identificação com a razoabilidade da norma expressa pelo adulto educador. No primeiro caso, a obediência deriva exclusivamente da autoridade; no segundo, deriva também da confiança. Ambos os tipos de obediência são indispensáveis para a formação da criança. É preciso preparar a criança para reconhecer, obedecer e respeitar, quando adulta, "leis que deverá seguir corretamente como cidadão, ainda que não lhe agradem" (KANT, 2002, p. 77).

\section{A FORMAÇÃo DA MORALIDADE PARA CUIDAR DO CARÁTER}

Se acreditarmos fazer sentido apresentar às crianças atitudes e normas a serem cumpridas por inclinação, também será fundamental que outras coisas lhes sejam prescritas para serem seguidas exclusivamente por dever. Kant extrapola essa sugestão, indicando o seguinte: "supondo-se que a criança não entenda o dever, melhor 
assim; e, supondo-se que algo seja dever dela, por ser criança, ela verá que é seu dever como ser humano" (KANT, 2002, p. 78). Nesse sentido, o autor explicita aquilo que virá sublinhado nos textos diretamente voltados para comentar sua plataforma moral. O dever é regido por uma estrutura específica da racionalidade. Todavia, se "fazer algo por dever equivale a obedecer à razão, falar a respeito do dever às crianças é trabalho perdido" (KANT, 2002 , p. 80), em virtude de ser a infância uma etapa de vida heterônoma quanto ao entendimento e quanto à vontade. A princípio, a criança obedece com receio da punição que se seguirá à possível transgressão.

Em algumas situações, será cabível recorrer ao sentimento de vergonha da criança. Esse sentimento constitui um dos primeiros traços indicadores do caráter moral na formação das novas gerações. Diz o autor sobre o tema:

Aqui é oportuno recorrer ao sentimento de vergonha, pois que a criança o compreende muito bem. O rubor nos denuncia quando mentimos; mas, isso não é uma prova de ter mentido ou de mentir. Frequentemente ficamos ruborizados pela impudência dos outros, quando nos acusam de alguma falta. Não se deve de modo algum tentar arrancar a verdade da boca das crianças por meio de punições, mesmo que sua mentira pudesse acarretar algum dano; elas seriam nesse caso punidas pelo próprio dano. A única pena que convém aos mentirosos é a perda da estima (KANT, 2002, p. 82).

A moralidade é composta, na perspectiva kantiana, quase exclusivamente pelo universo dos deveres. ${ }^{8}$ Os deveres humanos incluem a relação do sujeito consigo próprio e perante os outros, remetendo-se, portanto, a toda a Humanidade. É o dever consigo mesmo que conduz o jovem a reconhecer o patamar da dignidade em sua própria pessoa. Será, por sua vez, o reconhecimento de deveres perante os outros que possibilita a descoberta de um princípio regulador da acepção de direitos constitutivos da condição humana. Diz Kant que "o homem, quando tem diante dos olhos a ideia de Humanidade, critica a si mesmo; Nessa ideia ele encontra um modelo com o qual se compara a si mesmo" (KANT, 2002, p. 91).

É preciso orientar as crianças e os jovens e a identificar a moralidade com a perspectiva do dever e da imagem mental da lei: "devo considerar uma ação como valiosa, não porque se adapta à minha inclinação, mas porque através dela eu cumpro o meu dever" (KANT, 2002, p. 106). As leis que impomos a nós mesmos, no limite, irão contrariar as "tendências originárias para todos os vícios" (KANT, 2002, p. 95) que inevitavelmente trazemos dentro de nós. $\mathrm{O}$ instinto nos impulsiona para efetivar inclinações, e a razão precisará fazer o movimento contrário, de nos dirigir para o bem.
A criança deverá confiar em si mesma, mas modestamente, posto que:

Torna-se moral apenas quando eleva a sua razão até aos conceitos do dever e da lei. Pode-se, entretanto, dizer que o homem traz em si tendências originárias para todos os vícios, pois tem inclinações e instintos que o impulsionam para um lado, enquanto sua razão o impulsiona para o contrário (KANT, 2002, p. 95).

Assim como sua ética, e decorrente dela, a proposta pedagógica de Kant tem por pilares dever e princípios:

$\mathrm{Na}$ educação tudo depende de uma coisa: que sejam estabelecidos bons princípios e que sejam compreendidos e aceitos pelas crianças. Estas devem aprender a substituir ao ódio o horror do que é nojento e inconveniente; a aversão interior em lugar da aversão exterior diante dos homens e das punições divinas; a estima de si mesmas e a dignidade interior em lugar da opinião dos homens; o valor intrínseco do comportamento e das ações em lugar das palavras e dos movimentos da índole; o entendimento em lugar do sentimento; a alegria e a serenidade no bom humor em lugar da devoção triste, temerosa e tenebrosa (KANT, 2002, p. 96).

Kant concluirá sua preleção sobre os propósitos da pedagogia alertando para a importância de se ensinar aos jovens o valor identificado com o cumprimento do dever:

Deve-se orientar o jovem à Humanidade no trato com os outros, aos sentimentos cosmopolitas. Em nossa alma há qualquer coisa que chamamos de interesse: 1) por nós próprios; 2) por aqueles que conosco cresceram; e, por fim, 3) pelo bem universal. É preciso fazer os jovens conhecerem esse interesse para que eles possam por ele se animar. Eles devem alegrar-se pelo bem geral mesmo que não seja vantajoso para a pátria, ou para si mesmos. Convém orientá-los a dar pouco valor ao gozo dos prazeres da vida. Assim, perderá o temor pueril da morte. É preciso demonstrar aos jovens que o prazer não deixa conseguir o que a imaginação promete. É preciso, por fim, orientá-los sobre a necessidade de, todo dia, examinar a sua conduta, para que possam fazer uma apreciação do valor da vida, ao seu término (KANT, 2002, p. 106-107).

Como diz Dalbosco sobre a pedagogia de Kant, a educação permite que a ideia de realização se materialize para além de sua função normativa. Essa realização que é alcançada pelo continuado processo de formação - constitui o desenvolvimento das predisposições naturais do ser humano. As disposições do ser em direção ao seu aperfeiçoamento propiciam um constante movimento de realização; e este corresponde a uma "atitude de 
pensamento, caracterizada pela arte de pensar por conta própria, que capacite a ação humana a buscar um possível estado futuro melhor" (DALBOSCO, 2004, p. 8) -, tomando sempre a condição humana como um fim e jamais como meio.

O campo da moralidade apresenta-se como território a ser construído pela ação humana; dado que o homem "não é bom nem mau por natureza, porque não é um ser moral por natureza" (KANT, 2002, p. 95). Alçarse ao patamar de ser moral requererá o exercício da capacidade de conduzir sua razão a postular leis para si própria. E isso constitui o aprendizado de uma vida. Mais do que isso, supomos que as lições de Kant sobre a pedagogia, consistindo em um arremate de sua filosofia moral, corroboram a perspectiva de que podemos, sim, compreender o território da ética como uma das matérias necessárias para ensinar pedagogia.

\section{CONSIDERAÇÕES FINAIS}

Vivemos hoje, nesse princípio de século XXI, uma situação social para cuja compreensão valerá a pena anotar alguns preceitos do debate teórico acerca da moralidade. As novas gerações, criadas em um ambiente social, nacional e familiar que presenciou progressiva ampliação do leque dos direitos, por vezes, parecem carecer de que seja demonstrado a elas que, correspondendo a cada um dos direitos, há sempre um dever como contraponto. A sociedade democrática exige, indelevelmente, diálogo entre direitos e deveres. Pensar tal diálogo é repor o debate sobre a ética. Julgamos que hoje esse é o grande desafio dos estudos da filosofia da educação. ${ }^{9}$

Em qualquer reflexão sobre a moral, será necessário "colocar uma questão que é extramoral: é o mundo constituído de modo a favorecer a realização da moralidade?" (LEBRUN, 2001, p. 103). Alguns dirão que o julgamento sobre a questão do bem nos dias de hoje não pode ter por referência nada além dos valores expressos pelos sujeitos ou pelas comunidades que os falam. A ética seria, sob tal ponto de vista, um território circunscrito a particularidades dos espaços e dos tempos. Outros compreendem que, a despeito da necessidade de reconhecimento do lugar da diversidade na discussão antropológica, pode-se, ainda, encontrar algumas âncoras que possibilitem o estabelecimento de patamares comuns da discussão sobre a moral. De todo modo, poderíamos aqui refletir um pouco sobre esse assunto.

Isso requer, obviamente, meditar sobre os valores do mundo, dialogar com eles. Mais do que isso: parece importante retomar os fios dessa discussão para identificar instâncias de possibilidade de se alcançar alguma universalidade em matéria de ética. Se a liberdade é a capacidade humana de agir de acordo com princípios, para que se possa pensar na possibilidade de se discutir com os estudantes o tema da ética, será indispensável a introdução em sala de aula da discussão sobre os valores.

Ao educar, de alguma maneira, debatemo-nos com valores. Quais valores escolheremos? Como falar sobre eles com nossos alunos? Valores devem ser abordados apenas enquanto exemplos ou é possível desenvolver em sala de aula, nos diferentes níveis de ensino, alguma meditação sobre a matéria da moral? Quando educamos, propomo-nos a formar juízos, mas pretendemos também formar corações - contribuir para a formação do caráter. Nesse sentido, vale a pena reportarmo-nos, junto a nossos alunos - especialmente aqueles estudantes de cursos de formação de professores -, a algum nível de debate ético.

Enfim, recordar - como aqui se buscou fazer autores como Kant, com o propósito de emprestar alguns princípios de suas específicas reflexões sobre ética, foi um exercício de recomposição de um tema que é comum a diversas realidades pedagógicas deste princípio do século XXI. Nossa finalidade primeira foi recordar alguns significados depreendidos da leitura de autor clássico; até porque, como magistralmente assegura Italo Calvino: "os clássicos são aqueles livros que chegam até nós trazendo consigo as marcas das leituras que precederam a nossa e atrás de si os traços que deixaram na cultura ou nas culturas que atravessaram" (CALVINO, 2009, p. 18). E, por ser assim, existe um debate antigo no domínio da ética que repercute em nossa contemporaneidade e que poderá e deverá se tornar matéria de escola. Pensar sobre os critérios do bem não será tarefa desnecessária quando se projeta a construção de sociedades mais solidárias, mais justas e mais fraternas.

\section{REFERÊNCIAS}

ARENDT, Hannah. Entre o passado e o futuro. 5. ed. São Paulo: Perspectiva, 2000.

ARISTÓTELES. Arte poética. In: ARISTÓTELES; HORÁCIO; LONGINO. A poética clássica. Tradução de Jaime Bruna. São Paulo: Editora Universidade de São Paulo; Cultrix, 1981.

BARROS, Gilda Naécia Maciel. Rousseau e a questão da cidadania. Disponível em: <http://www.hottopos.com/ convenit2/rousseau.htm>. Acesso em: 04 out. 2008.

BARROS, Roque Spencer Maciel de. Meditação sobre Rousseau. São Paulo: USP, Centro Regional de Pesquisas Educacionais, 1963. (Separata do v. 6)

BILBENY, Norbert. La revolución en la ética: hábitos y creencias en la sociedad digital. Barcelona: Anagrama, 1997.

BOBBIO, Norberto. Direito e Estado no pensamento de Emanuel Kant. São Paulo: Mandarim, 2000.

CALVINO, Italo. Por que ler os clássicos? São Paulo: Companhia das Letras, 2009.

CASSIRER, Ernst. A questão Jean-Jacques Rousseau. Tradução de Erlon José Paschoal. São Paulo: Unesp, 1999. 
COMMELIN, P. Mitologia grega e romana. Tradução de Eduardo Brandão. São Paulo: Martins Fontes, 2008.

CRAMPE-CASNABET, Michèle. Kant: uma revolução filosófica. Tradução de Lucy Magalhães. Rio de Janeiro: Zahar, 1994.

DALBOSCO, Cláudio Almir. Da pressão disciplinada à obrigação moral: esboço sobre o significado e o papel da pedagogia no pensamento de Kant. Educação e Sociedade, Campinas, v. 25, n. 89, p. 1-12, set./dez. 2004. Disponível em: <http:/www.scielo.br/scielo.php?script=sci arttext\&pid=S0101-73302004000400012\&lng=en\&nrm=iso>. Acesso em: 11 mar. 2011.

DALBOSCO, Cláudio Almir; EIDAM, Heinz. Moralidade e educação em Kant. Ijuí: Editora Unijuí, 2009.

FERRY, Luc. Kant: uma leitura das três críticas. Rio de Janeiro: Difel, 2009.

FREIRE, Sônia Barreto. Do co-pertencimento das duas metafísicas de Kant na implementação do seu projeto pedagógico. Revista do Mestrado em Educação, Universidade Federal do Sergipe, Núcleo de Pós-Graduação em Educação, v. 10, p. 43-50, jan./jun. 2005.

FRANCISCO, Maria de Fátima Simões. Autoridade e contrato pedagógico em Rousseau. In: AQUINO, Júlio Groppa (Org.). Autoridade e autonomia na escola: alternativas teóricas e práticas. 2. ed. São Paulo: Summus, 1999.

FRANCISCO, Maria de Fátima Simões. Notas acerca da educação doméstica e educação pública no Emílio de Rousseau. Notandum, São Paulo, ESDC/CEMOrOC-Feusp/IJI; Porto, Universidade do Porto, n. 16, p. 53-64, 2008. Disponível em: $<$ http://www.hottopos.com/notand16/index.htm $>$. Acesso em: 10 jul. 2009.

GOLDSCHMIDT, V. Individu et communauté chez Rousseau. In: BÉNICHOU, P. et al. Pensée de Rousseau. Paris: Seuil, 1984. p. 147-161.

HERMANN, Nadja. Ética e educação. Belo Horizonte: Autêntica, 2014.

HÖFFE, Otfried. Immanuel Kant. Tradução de Christian Viktor Hamm e Valério Rohden. São Paulo: Martins Fontes, 2005.

KANT, Immanuel. Crítica da razão prática. Tradução de Artur Morão. Lisboa: Edições 70, 1987.

KANT, Immanuel. Fundamentação da metafísica dos costumes. Tradução de Paulo Quintela. Lisboa: Edições 70, 1988.

KANT, Immanuel. Resposta à pergunta: que é o Iluminismo? (1784). In: KANT, Immanuel. A paz perpétua e outros opúsculos. Tradução de Artur Morão. Lisboa: Edições 70, 1989.

KANT, Immanuel. Sobre a pedagogia. Tradução de Francisco Cock Fontanella. 3.ed. Piracicaba: Unimep, 2002.

KANT, Immanuel. Education. Tradução de Annette Churton. Michigan: University of Michigan Press, 2004a.

KANT, Immanuel. Réflexions sur l'éducation. Tradução de Alexis Philonenko. Paris: J. Vrin, 2004b.

LA TAILlE, Yves de. Moral e ética. Porto Alegre: Artmed, 2006.
LEBRUN, Gérard. Sobre Kant. São Paulo: Iluminuras, 2001.

MACHADO, Lourival Gomes. Homem e sociedade na teoria política de Jean-Jacques Rousseau. São Paulo: Martins; Editora da Universidade de São Paulo, 1968.

MARQUES, José Oscar de Almeida (Org.). Verdades e mentiras: 30 ensaios em torno de Jean-Jacques Rousseau. Ijuí: Editora Unijuí, 2005.

MARQUES, José Oscar de Almeida (Org.). Reflexos de Rousseau. São Paulo: Humanitas, 2007.

MENEZES, Edmilson. Kant e a pedagogia. Educação e Sociedade, Campinas, v. 3, n. 43, p. 463-477, 1992.

MENEZES, Edmilson. Kant e a educação das luzes. Educação e Filosofia, Uberlândia, v. 4, n. 27/28, p. 113-127, 2000.

MENEZES, Edmilson. Dignidade e educação em Kant. In: BERGER, Miguel André (Org.). A pesquisa educacional e as questões da educação na contemporaneidade. Maceió: Editora da Universidade Federal de Alagoas, 2010. p. 200-211.

PUIG, Josep Maria. A construção da personalidade moral. São Paulo: Ática, 1998.

PHILONENKO, Alexis. Introduction: Kant et le problème de l'éducation. In: KANT, Immanuel. Réflexions sur l'éducation. Tradução de Alexis Philonenko. Paris: J. Vrin, 2004.

PINHEIRO, Celso de Moraes. Kant e a educação: reflexões filosóficas. Caxias do Sul: Educs, 2007.

POLLA, Cauê Cardoso. O ABC do cosmopolitismo: Kant e a educação. São Paulo, tese (doutorado) - São Paulo, FFLCH/ USP, 2013.

PORTA, Mario Ariel Gonzalez. A filosofia a partir de seus problemas: didática e metodologia do estudo filosófico. São Paulo: Loyola, 2002.

RAWLS, John. História da filosofia moral. São Paulo: Martins Fontes, 2005.

ROSSETTI, Livio. Introdução à filosofia antiga: premissas filológicas e outras "ferramentas de trabalho". São Paulo: Paulus, 2006.

ROUSSEAU, Jean-Jacques. Do contrato social: ensaio sobre a origem das línguas. Discurso sobre a origem e os fundamentos da desigualdade entre os homens. Discurso sobre as ciências e as artes. In: ROUSSEAU, Jean-Jacques. Tradução de Lourdes Santos Machado. 3. ed. São Paulo: Abril Cultural, 1983. p. 321 352. (Col. Os Pensadores)

ROUSSEAU, Jean-Jacques. Oeuvres complètes - 2: oeuvres philosophiques et politiques; des premiers écrits au Contrat social (1735-1762). Paris: Seuil, 1971.

ROUSSEAU, Jean-Jacques. Oeuvres complètes - 3: oeuvres philosophiques et politiques; de l'Émile aux derniers écrits politiques (1762-1772). Paris: Seuil, 1971.

ROUSSEAU, Jean-Jacques. Emílio ou da educação. Tradução de Sérgio Milliet. 3.ed. São Paulo: Difel, 1979.

ROUSSEAU, Jean-Jacques. Projeto para a educação do Senhor de Sainte-Marie. Florianópolis: Paraula, 1994.

ROUSSEAU, Jean-Jacques. Ensaios pedagógicos. Tradução e apresentação: Priscila Grigoletto Nacarato. Bragança Paulista: Comenius, 2004. 
SANTOS, Robinson. Kant e a possibilidade de uma educação cosmopolita. Revista do mestrado em educação, Universidade Federal do Sergipe, Núcleo de Pós-Graduação em Educação, v. 10, p. 29-42, jan./jun. 2005.

STAROBINSKI, Jean. J.-J. Rousseau: la transparence et l’obstacle. Paris: Gallimard, 1971.

THOUARD, Denis. Kant. São Paulo: Estação Liberdade, 2004.

TORRES, Salvador Mas. Ethos y polis: una historia de la filosofía práctica en la Grecia clásica. Madrid: Istmo, 2003.

TUGENDHAT, Ernst. Lições sobre ética. Tradução de Róbson Ramos dos Reis et al. 4. ed. Petrópolis: Vozes, 2000.

VANCOURT, Raymond. Kant. Tradução de António Pinto Ribeiro. Lisboa: Edições 70, 2003.

VANDEWALLE, Bernard. Kant: educación y crítica. Tradução de Horácio Pons. Buenos Aires: Nueva Visión, 2005. VIEIRA, Trajano. Édipo rei de Sófocles. São Paulo: Perspectiva; Fapesp, 2001.

\section{NoTAS}

1 "Móbil da moralidade, o respeito não é o seu fundamento. Esta, com efeito, implica essencialmente um imperativo que se impõe a nós de uma maneira absoluta. Todas as coisas, na natureza, agem segundo leis; os seres racionais também; mas as suas leis, eles conhecem-nas previamente e a vontade não é neles mais que o poder de agir em conformidade com regras que exprimimos; um ser no qual razão e vontade constituíssem apenas um, e que estivesse liberto de toda a influência estranha, escolheria sempre o que a razão considera como bom. Em contrapartida, um ser finito, cuja vontade sente a atração de móbeis sensíveis, por vezes em desacordo com a lei, não se conforma inevitavelmente com esta; e para ele, a lei apresenta-se sob o aspecto de uma imposição; de um mandamento, de um imperativo. O imperativo supõe portanto uma vontade subjetivamente imperfeita, à qual é pedido que se decida de acordo com regras, não segundo os impulsos da sensibilidade" (VANCOURT, 2003, p. 34-35).

2 Robinson dos Santos observa que, embora não se possa dizer que Kant tenha escrito um tratado sobre a Pedagogia, "os apontamentos que restaram de suas preleções de Pedagogia, que Friedrich Theodor Rink reuniu, possivelmente fazendo alguns acréscimos para dar aos fragmentos uma aparência de organicidade, e encaminhou para publicação com o consentimento de Kant um ano antes de sua morte" (SANTOS, 2005, p. 31).

3 Hannah Arendt posteriormente retomará essa ideia, destacando que "basicamente, estamos sempre educando para um mundo que ou já está fora dos eixos ou para aí caminha, pois é essa a situação humana básica, em que o mundo é criado por mãos mortais e serve de lar aos mortais durante tempo limitado. O mundo, visto que feito por mortais, se desgasta, e, dado que seus habitantes mudam continuamente, corre o risco de tornarse mortal como eles. Para preservar o mundo contra a mortalidade de seus criadores e habitantes, ele deve ser, continuamente, posto em ordem. O problema é simplesmente educar de tal modo que um pôr-em-ordem continue sendo efetivamente possível, ainda que não possa nunca, é claro, ser assegurado. Nossa esperança está pendente sempre do novo que cada geração aporta; precisamente por basearmos nossa esperança apenas nisso, porém, é que tudo destruímos se tentarmos controlar os novos de tal modo que nós, os velhos, possamos ditar sua aparência futura. Exatamente em benefício daquilo que é novo e revolucionário em cada criança é que a educação precisa ser conservadora; ela deve preservar essa novidade e introduzi-la como algo novo em um mundo velho, que, por mais revolucionário que possa ser em suas ações, é sempre, do ponto de vista da geração seguinte, obsoleto e rente à destruição" (ARENDT, 2000, p. 243)
4 “A educação primeira deve, portanto, ser puramente negativa. Ela consiste, não em ensinar a virtude ou a verdade, mas em preservar o coração do vício e o espírito do erro. Se pudésseis conduzir vosso aluno são e robusto até a idade de doze anos, sem que ele soubesse distinguir sua mão direita de sua mão esquerda, logo às vossas primeiras lições os olhos de seu entendimento se abririam para a razão. Sem preconceitos, sem hábitos, nada teria ele em si que pudesse contrariar o resultado de vossos cuidados. Logo ele se tornaria, em vossas mãos, o mais sensato dos homens; e, começando por nada fazer, tereis feito um prodígio de educação" (ROUSSEAU, 1979, p. 80).

5 "Os primeiros choros das crianças são solicitações: se não tomarmos cuidado, logo se tornam ordens; começam pedindo assistência, acabam fazendo-se servir. Assim, de sua própria fraqueza, de que provém inicialmente o sentimento da sua dependência, nasce a seguir a ideia de império, de domínio; mas essa ideia, sendo menos provocada por suas necessidades do que por nossos serviços, começam-se a perceber os efeitos morais cuja causa imediata não está na natureza; e vê-se desde já por que, desde a primeira infância, importa descobrir a intenção secreta que dita o gesto ou o grito" (ROUSSEAU, 1979, p. 47).

${ }^{6}$ Rousseau é, porém, muito mais refratário aos efeitos da instrução do que Kant. Rousseau dirá sobre o tema: "lembrai-nos sempre de que o espírito de minha instituição não é ensinar à crianças muitas coisas e sim não deixar entrar em seu cérebro senão ideias justas e claras. Que não saiba nada, pouco me importa, conquanto não se engane, e só ponho verdades em sua cabeça para defendê-la dos erros que aprenderia em seu lugar. A razão, o juízo chegam lentamente, os preconceitos acorrem em multidão; é destes que cumpre preservá-lo" (ROUSSEAU, 1979, p. 180).

7 "Piaget formulou três períodos em relação ao desenvolvimento da noção de justiça. O primeiro período é o da justiça entendida como obediência (crianças de seis a oito anos): o dever está associado à justiça e a desobediência à injustiça. A justiça nesta etapa é equivalente ao conteúdo das normas impostas pelos adultos. O segundo período é o da justiça entendida como igualdade (crianças de oito a onze anos):o igualitarismo se impõe como critério de justiça, acima da autoridade adulta; o justo é um tratamento igual para todos, sem considerar as circunstâncias pessoais de cada sujeito. $\mathrm{O}$ terceiro período é o da justiça como equidade: superase o igualitarismo em favor de uma igualdade sensível às situações particulares e ao tratamento que cada pessoa merece" (PUIG, 1998, p. 53).

8 Note-se que, embora para Kant não situe a moralidade no domínio das virtudes, em seu trabalho Sobre a pedagogia, ele assim assinala o contraponto entre os vícios e as virtudes. Diz o autor que "os vícios são: ou os da malignidade, ou os da baixeza, ou os da estreiteza de ânimo. À primeira espécie pertencem a inveja, a ingratidão e a alegria pela desgraça alheia. À segunda, a injustiça, a infidelidade (falsidade), a incontinência, tanto na dissipação dos próprios bens como na da própria saúde (intemperança) e da própria reputação. À terceira, a dureza de coração, a avareza e a preguiça (moleza). As virtudes são: ou de puro mérito, ou de estrita obrigação, ou de inocência. A primeira classe compreende: a magnanimidade (que consiste no conter-se, seja na cólera, seja no amor da comodidade e das riquezas), a beneficência e o domínio de si mesmo. Pertencem à segunda classe: a lealdade, a decência e a pacificidade. Pertencem, enfim, à terceira classe: a honradez, a modéstia e a temperança" (KANT, 2002, p. 94-95).

9 O território da Filosofia da Educação como campo do conhecimento, que não é apenas um apêndice da Filosofia, possibilita-nos tomar de empréstimo reflexões de vários autores e entrecruzá-los, de modo a compreender o entrelace do pensamento pedagógico no universo do que poderíamos qualificar por história das ideias educativas. Como se vê, este ensaio procura entretecer fontes e referências de vários momentos, a partir de bibliografia que envolve leitura de originais e/ou confronto entre traduções.

Artigo recebido em março 2014.

Aprovado em abril 2014. 